PART IV.-NOTES AND NEWS.

EARLY in the morning of the 5th of March last, at the Lawn, Hanwell, after a brief illness, entered into his everlasting rest, aged seventy-one years, John Conolly, M.D., D.C.L. On the morning of the previous day he had sunk down on the floor and been unable to rise, though without being insensible. For a short time afterwards he had some difficulty in expressing himself; he could not always find the right word, but occasionally made use of a wrong one; all the while being quite conscious of his difficulty, and painfully anxious to assure those around that he was perfectly sensible of their presence and of all that was said. It was very characteristic of that careful attention to propriety of language as well as of the extreme courtesy which distinguished him throughout life that he grieved and apologized for his inability to express himself correctly, even when he was expressing himself quite well. His longing desire was to be at rest, and his earnest hope, that he might not recover from this attack as he had recovered from former like attacks. "I have only one wish," he exclaimed-_" to die ; but God's will be done." In the evening he had quite recovered his power of expression, spoke cheerfully, and uttered many kindly wishes, still praying that he might not recover, though fearing that he might. At 3 a.m. of the following morning he was attacked with paralysis of the right side and violent epileptiform convulsions, which followed one another in quick succession for two hours; he was quite insensible; and when the convulsions ceased he passed gently away, as one who falls to sleep after a long day's labour. His body is buried in the Kensington Cemetery at Hanwell. His name liveth for evermore. 


\section{Notice of the late Dr. Conolly.}

IN the next number of the 'Journal of Mental Science' will appear a full memoir of the late Dr. Conolly ; meanwhile we quote the following notice which appeared in the 'Medical Times and Gazette :'

Early in the morning of Monday, March 5, there passed to his everlasting and long-desired rest, after a few hours of illness, one whose name will always be identified with a great and noble work. JoHs Conorrr, to whose earnest convictions, faithful perseverance against all difficulties, and zealous labours, the modern humane treatment of the insane mainly owes its practical origin and its consummate triumph, is henceforth only a name in history. But if there is a good title to the gratitude of mankind in the alleviation of infinite human suffering-if there is a title to immortal fame in the faithful performance of a great and good work of reform, the memory of which must last as long as human sympathies endure-then his is a name which the world will not let die, and his a glory of which nothing ever can bereave him. He made the best part of a life having many vicissitudes a noble part of human progress: by his death individual ties and sympathies, virtues and foibles, all fall away, and the greatness of his life, standing more clearly out, becomes the concern, as it is the gain and honour, of mankind.

'The late John Conolly, M.D., was born at Market Rasen, in Lincolnshire, his mother being of the name and family of the present Laureate. His father dying when be was only a few years old, he was early sent from home to school; and often and earnestly in after life did he revert to the dreary misery of that period, in which the semblance of learning was mechanically imparted by aid of frequent punishments. That he had obtained by stealthy purchase some volumes of the Spectator and a copy of the "Pilgrim's Pro. gress" were gleams of bright reminiscence of that dark period; and he read and re-read the essays of Addison with a delight to which he ever loved to recur, and which we may well understand in one who wrote as elegantly and correctly as he always wrote. It may well be, indeed, that the influence of Addison's easy and graceful style contributed to the formation of his own correct taste in composition; for to the last scarce anything more offended his refined sensibility than coarseness and slovenliness in the expression and structure of a sentence.

Soon after leaving school, and when not yet eighteen years of age, he entered a Militia Regiment as ensign, and was stationed at different places both in Scotland and Ireland. The life of thoughtless pleasure and reckless excitement, common at that time amongst the officers of a regiment, could not fail to be for a time attractive to a young ensign of lively and impulsive temperament, with a passionate love of genial social intercourse; but it marks the superiority of his mental culture, as well as the skill of the pen, which has often pleased and instructed the readers of this journal, that other officers used commonly to have recourse to his help to compose their important letters. Not long after leaving the regiment, and when only twenty-two years of age, he married, and went with his wife to France, where in 8 beautiful cottage near Tours, afterwards occupied by the poet Béranger, he passed in unheeding enjoyment the happiest year of his life. But at the end of a year, and when a child had been born, it became necessary to think seriously of adopting some profession or other regular means of livelihood. After consulting friends, one of whom was the aniiable Dr., now Sir Arnold Knight, he resolved to commence the study of Medicine at Edinburgh. Leaving, then, behind him, with natural reluctance, his beautiful cottage and the unmingled poetry of life, he set forth with his wife and child to Edinburgh, and began in earnest the work of a medical student. It was 8 great and dreary change, but its weight was lightened by the friendly hospi: tality of many of the illustrious men who at that time adorned the northern 
capital, and who were attracted to the student by the amiable disposition, courteous manners, and refined culture which distinguished him through life.

On graduating as a Doctor the subject of his thesis was "Insanity ;" his attention being thus early occupied with the subject which was to be the field of his future labours and triumph. It will be errone(ous, however, to suppose that he then foresaw the future scope of his work, or that he had any definite uim which he proposed to himself to work for. No man who has done anything great in the world of practical activity ever had such predetermined aim thou h he might think so afterwards; there is much blind struggling, admidst shifting uncertainties and untoward circumstances, before the appointed man and his work come together; and it is that which lies deep in his nature, that which is beneath will and beneath consciousness, and of which he can give no account, that unconsciously impels him on his course, and inspires him with the faith necessary to success.

On leaving Edinburgh, Dr. Conolly first went to Lewes, with the object of there settling in practice, but moved after three months to Chichester, where, about the same time, the late Sir John Forbes established himself. Their short rivalry was the foundation of a lasting friendship, and they were afterwards associated together as juint editors of the British and Foreign Medical Review, and with Dr. Tweedie in the production of the Cyclopedia of Medicine. But Chichester was not equal to the support of two physicians, and Dr. Conolly, after residing there a year, removed to Stratford-on-Avon, where he practised successfully for several years, and accomplished much literary work. Here, too, he enjoyed the friendship of the great Whig scholar and champion, Dr. Parr, the severest of schoolmasters, but the most kind-hearted of men. Leaving Stratford-on-Avon to assume the Professorship of the Principles and Practice of Medicine at University College, London, he established himself in Gloucester Place, and was during the time of his residence in London one of the most active members of the "Society for the Diffusion of Useful Knowledge." But as practice did not come sufficiently quickly, and as divisions existed in the councils of the college, and bickerings and heart-burnings within its walls, while no hospital had yet been built, he resigned his appointment, after bolding it for three years, and returning to the neighbourhood of Stratford, settled at Warwick. It was after he had been there six years that the office of Resident Physician to the Hanwell Asylum became vacant, and that he applied for the appointment, being defeated only by the casting vote in favour of Dr. Millingen. But a year afterwards the office was again vacant, and his second application was happily successful. And now at last, after many wanderings and much suffering, he had found the true sphere of his labours: he was appointed Resident Physician in June, 1839, and in September of that year every form of mechanical restraint bad been banished from the asylum. It was some time befure the non-restraint system was generally accepted as practicable: much opposition had to be encountered and overcome; but the experiment made on so large a scale in an institution containing nearly a thousand patients, suffering from every variety of insanity, proved beyond all question not only the entire practicability, but the great benefit of the humane system of treatment. The complete record of its progress is contained in the admirable reports of the Hanwell Asylnm from 1839 to 1844. In the latter yead Dr. Conolly resigned his appointment at the asylum, but continued to devote his energies to the promotion of every good sçheme having for its object the improvement of the condition of the insane. In conjunc. tion with the late Dr. Reed, he was an active promoter and the constant supporter of the Idiot Asylum at Earlswood ; and his warmest desires were fixed on the establishment of long and sorely needed public asylums for the poor insane of the middle classes. 
Though it may justly be thought, perhaps, that one who did so much for the world was not adequately rewarded by it, when others who have not deserved so well have received great rewards, his services were not entirely unrecognised. A magnificent testimonial, consisting of a massive silver group of allegorical figures, together with his portrait, was presented to him in 1852 by public subscription; and in the same year the University of Oxford conferred upon him the degree of D.C.L. But his highest testimonial is the noble work which he has accomplished, and his highest honour will be in the grateful recognition of foreign lands and of future ages.

Of his literary works we cannot speak at length now. They are well known both in this and other countries; his book on the 'Construction and Management of Lunatic Asylums' is a standard work of authority, and his little work on " Hamlet," published two years ago, is one of the most graceful, learned, and philosophical essays that has ever proceeded from any pen. His extremely polished style, the careful construction of his sentences, the elegance and precision of his language, make whatever he wrote most interesting to read.

During the last few years of his life he had, in consequence of failing bealth, gradually retired from active practice; and daily occupied in the study of classical authors, English and Latin, he awaited with equanimity the great change. He had so lived that when the summons came he could meet it, not in fear and trembling; but, sustained by the consciousness of a good work well done, he willingly approached his grave as one who, the long day's task over, "wraps the drapery of his couch about him, and lies down to pleasant dreams." His end was sudden, as he had ever prayed that it might be ; and his intellect was perfectly unclouded until close upon the fatal termination, as he had hoped with an exceeding earnest hope that God would grant it might be. A sudden attack of hemiplegia was followed by severe unilateral convulsions, and in a little more than two hours he entered on his everlasting rest. He was 71 years of age.

"After life's fitful fever be sleeps well."

\section{Medico-Psychological Association.}

The Annual Meeting of the Medico-Psychological dssociation for 1866 will be held in Edinburgh, under the Presidency of Dr.W. A. F. Browone, Commissioner in Lunacy for Scotland, on Tuesday, the 31st July.

Communications, \&c., \&c., in reference to the Annual Meeting to be addressed to the Honorary Secretary (Dr. Harrington Tuke), 37, Albemarle St., London, W.

\section{Books Received, 1866.}

1. 'Verslag over den Staat der Gestichten voor Krauksinnigen in die Jaren, $1860,1861,1862$, und 1863 ; aan den minister van Binnenlandsche Zaken ingediend door de Inspecteur dier Gestichten, 1865.

2. 'A Manual for the Classification, Training, and Education of the FeebleMinded, Imbecile, and Idiotic.' By P. Martin Duncan, M.B. Lond., and William Millard. Longman and Co., 1866.

Will be revievoed in our next number.

3. 'Die Pathologischen Gewebenänderungen des Ohrknorpels und deren

Beziehungen zur Ohrblutgeschwulst.' Von Dr. Ludwig Meyer.

(4 Reprint from Virchow's 'Archiv,' $B$. XXXIII.)

4. ' Oeber die Behandlung des Delirium Tremens.' Von Dr. Ludwig Meyer.

1 Reprint from the Berlin Clinical 'Wochenschrift.'

5. 'Successful Removal of the Uterus and both Ovaries by Abdominal

Section.' By Horatio R. Storer, M.D., Boston, 1866.

(Reprinted from the 'American Journal of the Medical Seiences.' 